\title{
PENGARUH PELATIHAN DAN MODAL INTELEKTUAL TERHADAP KINERJA KEUANGAN PERUSAHAAN PERBANKAN YANG TERDAFTAR DI BURSA EFEK INDONESIA TAHUN 2012 - 2015
}

\author{
Gunar Rusli \\ Program Magister Akuntansi, Universitas Tarumanagara \\ gunar.rusli@yahoo.co.id
}

\begin{abstract}
ABSTRAK
Penelitian ini menyelidiki pengaruh dari pelatihan dan modal intelektual perusahaan terhadap perusahaan perbankan yang terdaftar di Bursa Efek Indonesia pada periode 2012 - 2015. Pada umumnya, perusahaan yang melakukan pelatihan dan memiliki modal intelektual yang tinggi akan memiliki kinerja keuangan yang lebih baik dibandingkan perusahaan sejenis yang kurang melakukan pelatihan dan kurang memiliki modal intelektual. Berdasarkan hal tersebut, penulis merumuskan hipotesis bahwa pelatihan dan modal intelektual berpengaruh pada kinerja keuangan perusahaan. Penelitian ini menggunakan metode analisis korelasi kanonikal untuk menyelidiki hubungan dan pengaruh pelatihan dan modal intelektual terhadap kinerja keuangan perusahaan. Hasil penelitian menunjukkan bahwa pelatihan dan modal intelektual memiliki hubungan dan pengaruh yang positif dan signifikan terhadap kinerja keuangan perusahaan.
\end{abstract}

Kata kunci: pelatihan, modal intelektual, VAIC, kinerja

\section{PENDAHULUAN}

Walau perekonomian dunia sedang mengalami perlambatan, namun perekonomian Indonesia mengalami pertumbuhan yang cukup baik dalam tahun 2016 - 2017. Pertumbuhan ekonomi ditengah-tengah persaingAn dunia secara tidak langsung menuntut semua perusahaan di Indonesia untuk selalu meningkatkan kinerjanya agar dapat bertahan dan dapat tetap bersaing di pasaran. Namun sektor perbankan di Indonesia mengalami pelemahan fungsi intermediasi dalam beberapa tahun terakhir dan tidak lagi membukukan kinerja keuangan yang fantastis. Hal ini terlihat dari rendahnya pertumbuhan kredit, naiknya rasio kredit bermasalah (nonperforming loan) dan sejumlah bank yang melakukan pemutusan hubungan kerja (PHK) pada karyawannya untuk mengurangi pengeluaran yang merupakan salah satu dari pengaruh perlambatan ekonomi global (Daniel, 2016; Rayanti, 2016; Liputan6.com, 2017).

Kinerja keuangan perusahaan pada umumnya diukur oleh beberapa instrument seperti laba, arus kas, Return on Asset, Return on Investment, dan lain-lain. Berdasarkan literatur yang ada, kinerja perusahaan dipengaruhi oleh faktor-faktor internal maupun eksternal. Salah satu faktor yang mempengaruhi kinerja adalah pelatihan karyawan. Dengan asumsi ceteris paribus, yaitu faktor-faktor lain tidak berubah, pelatihan karyawan memiliki pengaruh yang positif terhadap kinerja perusahaan (Efryns dan Zefanya, 2009; Lubis, 2008; Isabelle, Aragon, Jimenez dan Valle, 2012; Garcia, Cortes, Marco-Lajara dan Saez, 2004). Untuk keadaan tertentu, pelatihan tidak berpengaruh secara langsung terhadap kinerja keuangan perusahaan, tetapi harus diorientasikan ke pembelajaran dalam organisasi (organizational learning) dan disertai dengan tindak lanjut, dukungan serta keterlibatan dari manajemen agar hasil dari pelatihan tersebut berpengaruh pada kinerja keuangan (Aragon, Jimenez dan Valle, 2013 dan Dermol dan Cater, 2013). Hasil tinjauan literatur di atas menunjukkan adanya pertentangan antar hasil penelitian yang dilakukan terhadap pelatihan karyawan.

Faktor berikutnya adalah gaji dan kompensasi karyawan yang berpengaruh positif terhadap kinerja keuangan perusahaan. Kompensasi dan pembayaran gaji berdasarkan hasil yang dicapai terbukti berpengaruh dalam meningkatkan kinerja dan motivasi kerja karyawan. (Gielen, 2009, Bryson, Buraimo dan Simmons, 2011 dan Cyrenne, 2014). Berdasarkan literature tersebut, terlihat bahwa tidak ada pertentangan antara hasil penelitian yang dilakukan terhadap gaji dan kompensasi karyawan. 
Faktor ketiga yang mempengaruhi kinerja keuangan perusahaan adalah modal intelektual perusahaan (intellectual capital). Modal intelektual perusahaan merupakan kekayaan tidak berwujud perusahaan yang terdiri dari pengetahuan yang dimiliki karyawan perusahaan beserta pengetahuan yang terbentuk dalam peralatan dan jaringan yang berpartisipasi dalam kegiatan operasi perusahaan (Thomas Stewart, 1998). Literatur menunjukkan bahwa modal intelektual perusahaan secara simultan berpengaruh dan berkorelasi positif kepada kinerja perusahaan, terutama pada perusahaan perbankan, walaupun belum tentu semua elemennya, yaitu modal struktural, modal manusia dan modal yang dipekerjakan, secara parsial berpengaruh positif terhadap kinerja. Modal intelektual juga ditemukan tidak berpengaruh pada kinerja keuangan perusahaan di bidang ekspor di Serbia. Hal ini menunjukkan adanya pertentangan antar hasil penelitian yang dilakukan mengenai modal intelektual perusahaan. Pertentangan ini disebabkan oleh perbedaan efektivitas dari pemanfaatan keahlian karyawannya oleh masing-masing perusahaan, bagaimana karyawannya memaksimalkan kemampuan intelektual mereka untuk menaikan nilai perusahaan dan keadaan yang dialami perusahaan tersebut seperti reorganisasi dan resesi yang dialami (Ulum, Chariri dan Ghozali, 2008; Gruian, 2011; Janosevic dan Dzenopoljac, 2012; Ranani dan Bijani, 2014; Isanzu, 2015 serta Razafindrambinina dan Assegaf, 2015).

Faktor lain yang juga berpengaruh pada kinerja keuangan perusahaan adalah kegiatan tanggung jawab sosial perusahaan (Corporate Social Responsibility). Tanggung jawab sosial perusahaan berpengaruh positif terhadap kinerja perusahaan, yang berarti bahwa pelaksanaan kegiatan tanggung jawab sosial perusahaan dapat mendukung pencapaian kinerja keuangan perusahaan yang lebih baik (Choe, 2010; Flammer, 2013; Kadlubek, 2015; Rodriguez-Fernandez, 2016). Dalam keadaan tertentu, tanggung jawab sosial perusahaan berpengaruh negative terhadap kinerja perusahaan-perusahaan berskala besar (Zoubir, 2015) atau dalam keadaan lainnya tidak memiliki pengaruh sama sekali terhadap kinerja perusahaan (Brine, Brown dan Hackett, 2007). Tinjauan literatur lain menyatakan bahwa pengaruh tanggung jawab sosial perusahaan dimediasi faktor-faktor mediasi seperti modal intelektual perusahaan (Lin, Chang dan Dang, 2015). Maka, dapat disimpulkan bahwa masih terdapat perbedaan hasil penelitian mengenai pengaruh tanggung jawab sosial perusahan terhadap kinerja keuangan perusahaan.

Faktor selanjutnya adalah tata kelola perusahaan (corporate governance). Perusahaan yang menerapkan tata kelola perusahaan dengan baik dan memiliki kebijakan tata kelola perusahaan yang baik pada umumnya memiliki kinerja keuangan yang lebih baik dibandingkan dengan perusahaan yang tidak menerapkan tata kelola perusahaan dengan baik dan tidak memiliki tata kelola perusahaan yang baik. Maka, dapat disimpulkan bahwa tata kelola perusahaan berpengaruh positif terhadap kinerja keuangan perusahaan (Brown dan Gorgens, 2009, ; Claudiu-Marian, 2011; Nuryaman, 2012; Rambo, 2013; Ogege dan Boloupremo, 2014; Kara, Acar, Erdur dan Karabiyik, 2015; Ueng, 2016). Dari tinjauan literatur tersebut, tidak ditemukan adanya pertentangan antara hasil penelitian yang telah dilakukan terhadap tata kelola perusahaan. Faktor manajemen lingkungan yang dilakukan perusahaan juga memiliki dampak yang positif terhadap kinerja keuangan perusahaan. Perusahaan yang menerapkan manajemen lingkungan menunjukkan profitabilitas yang lebih tinggi dibandingkan dengan perusahaan yang tidak menerapkan manajemen lingkungan (Song, Zhao dan Zheng, 2016; Lucas and Noordewier, 2016). Hal ini juga menunjukkan tidak adanya pertentangan antara hasil penelitian yang dilakukan terhadap faktor manajemen lingkungan

Faktor inovasi dan gaya kepemimpinan manajemen dalam perusahaan memiliki pengaruh yang positif terhadap kinerja bisnis. Hal ini tercermin dari gaya kepemimpinan transaksional bagi industry kecil dan kepemimpinan transformasional untuk korporasi yang diterapkan oleh perusahaan-perusahaan di sektor industri dan sektor jasa di Istanbul (Yildiz, Basturk dan Boz, 2014).

Faktor lain yang mempengaruhi kinerja adalah penggunaan internet oleh karyawan. Penggunaan internet pada perusahaan besar dengan banyak cabang, franchise, dan afiliasi memiliki pengaruh yang positif terhadap 
kinerja keuangan perusahaan. Namun, penggunaan internet pada perusahaan kecil yang hanya memiliki satu kantor dan tidak banyak memiliki afiliasi ataupun franchise (Benjamin, Chinloy, Jud, dan Winkler, 2005).

Berdasarkan uraian tersebut, dapat kita ambil kesimpulan bahwa faktor-faktor yang mempengaruhi kinerja keuangan perusahaan antara lain:

1. Pelatihan

2. Gaji dan kompensasi

3. Modal intelektual perusahaan (Intellectual Capital)

4. Tanggung jawab sosial perusahaan (corporate social responsibility)

5. Tata kelola Berdasarkan tinjauan perusahaan

6. Manajemen lingkungan

7. Inovasi

8. Gaya kepemimpinan

9. Penggunaan internet

Literatur, faktor pelatihan, modal intelektual, struktur modal, tanggung jawab sosial perusahaan tata kelola perusahaan, manajemen lingkungan, inovasi, gaya kepemimpinan manajemen dan penggunaan internet memiliki pengaruh yang berbeda-beda terhadap kinerja keuangan. Perbedaan pengaruh tersebut pada umumnya disebabkan oleh keadaan internal dan eksternal dari populasi penelitian. Dari faktor-faktor yang memiliki hasil penelitian yang bertentangan, penelitian terbanyak adalah mengenai pelatihan dan modal intelektual, maka penulis tertarik untuk melakukan penelitian mengenai "Pengaruh Pelatihan dan Modal Intelektual Terhadap Kinerja Keuangan Perusahaan Perbankan yang Terdaftar di Bursa Efek Indonesia Tahun 2012 - 2015"

\section{METODE PENELITIAN}

Metode analisis data yang digunakan adalah analisis data statistik deskriptif dan analisis korelasi kanonikal. Data yang diambil adalah data kuantitatif yang berasal dari sumber data sekunder, yaitu laporan keuangan yang diterbitkan oleh perusahaan. Berdasarkan jenisnya, data yang akan digunakan adalah data panel, yaitu data yang memiliki dimensi waktu dan ruang. Untuk dapat menentukan sifat dan kekuatan hubungan antar dua variabel dan data panel tersebut, penelitian ini akan menggunakan statistik deskriptif dan analisis korelasi kanonikal.

\section{Analisis Korelasi Kanonikal}

Korelasi kanonikal merupakan suatu teknik analisis statistik yang digunakan untuk menentukan tingkat asosiasi linear antara dua kelompok variabel. Kelompok variabel yang dimaksud adalah kelompok yang terdiri dari dua atau lebih variabel, yang terdiri dari satu kelompok variabel bebas dan satu kelompok variabel terikat. Variat kanonikal akan terbentuk untuk setiap kelompok, di mana variat ini memiliki sifat yang sama seperti variat yang terbentuk dalam analisis regresi berganda. Berbeda dengan analisis regresi yang hanya mengakomodasi variat satu variabel bebas dengan variabel terikat, korelasi kanonikal dapat mengakomodasi variat beberapa variabel bebas dengan variat beberapa variabel terikat. (Hair, Black, Babin dan Anderson, 2010; Sarwono, 2017)

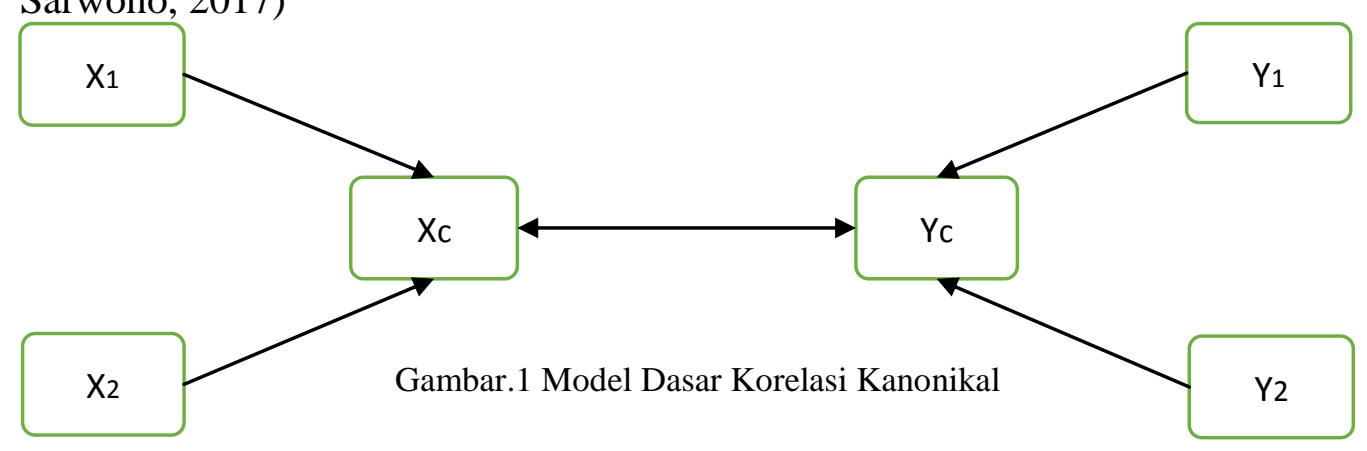


Keterangan:

$\mathrm{X}_{1} \quad=$ Variabel bebas 1

$\mathrm{X}_{2}=$ Variabel bebas 2

$\mathrm{X}_{\mathrm{c}} \quad=$ Kelompok variabel bebas

$\mathrm{Y}_{1} \quad=$ Variabel terikat 1

$\mathrm{Y}_{2}=$ Variabel terikat 2

$\mathrm{Y}_{\mathrm{c}} \quad=$ Kelompok variabel terikat

Model korelasi kanonikal memberikan keuntungan bagi peneliti dalam bentuk mengurangi peluang terjadinya kesalahan tipe I, yaitu ditemukannya hasil statistik yang signifikan saat hasil tersebut tidak ada. Kesalahan tipe ini pada umumnya terjadi pada model yang memiliki terlalu banyak uji statistik (Hair, Black, Babin dan Anderson, 2010).

Berdasarkan model dasar tersebut, model dalam penelitian ini adalah sebagai berikut

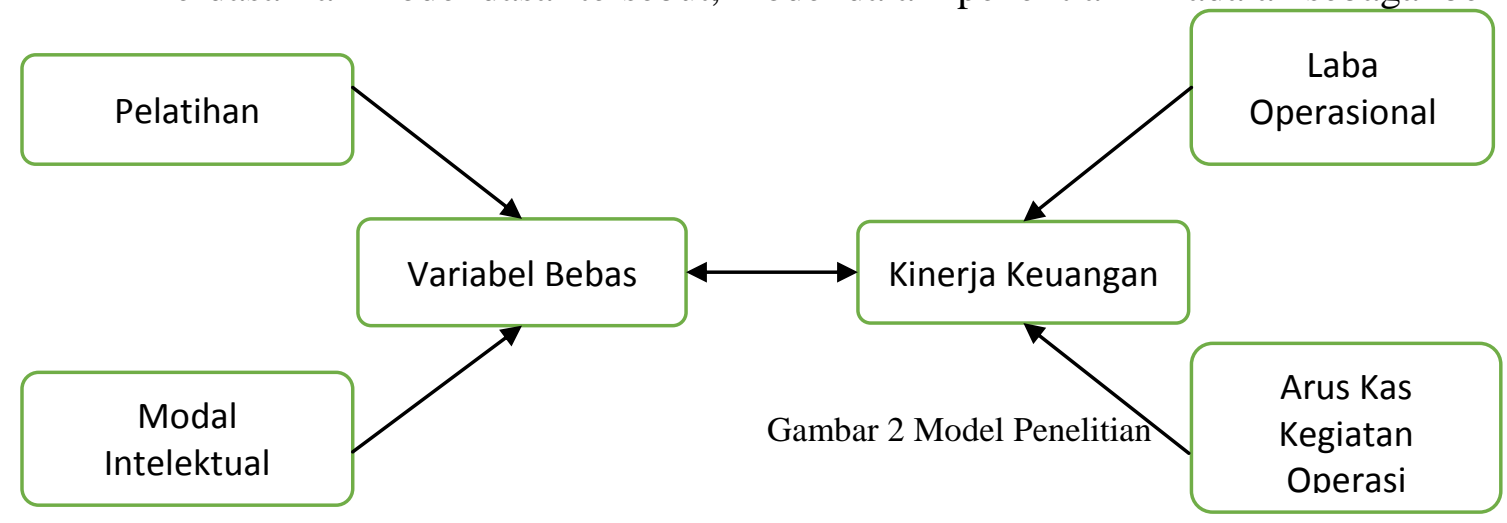

Dalam penelitian ini, analisis korelasi kanonikal akan dilakukan dengan bantuan SPSS (Statistical Product and Service Solution) Versi 23.0. Dalam penelitian ini terdapat dua gugus variabel, yaitu gugus variabel bebas $\left(\mathrm{X}_{1}\right.$ dan $\left.\mathrm{X}_{2}\right)$ dan gugus variabel terikat $\left(\mathrm{Y}_{1}\right.$ dan $\left.\mathrm{Y}_{2}\right)$. Penelitian ini akan menggunakan SPSS dengan cara sebagai berikut:

1. Aktifkan SPSS, lalu keluarkan data penelitian

2. Klik pilihan sebagai berikut: Analyze $>$ Correlate $>$ Canonical correlation

3. Masukkan variabel-variabel penelitian sesuai dengan kolom yang ada di SPSS.

\section{HASIL PENELITIAN DAN PEMBAHASAN}

Tabel 1 Canonical Correlations

\begin{tabular}{|l|r|r|r|r|r|r|r|}
\hline & Correlation & Eigenvalue & Wilks Statistic & F & Num D.F & Denom D.F. & Sig. \\
\hline 1 & .957 & 11.016 & .082 & 81.903 & 10.000 & 330.000 & .000 \\
2 & .094 & .009 & .991 & .374 & 4.000 & 166.000 & .827 \\
\hline
\end{tabular}

$\mathrm{HO}$ for Wilks test is that the correlations in the current and following rows are zero

Korelasi antara kelompok variabel bebas dengan kelompok variabel terikat adalah sebesar 0,957 atau 95,7\%. Berdasarkan klasifikasi korelasi oleh Sarwono (2006), kedua kelompok variabel tersebut memiliki korelasi yang sangat kuat dan positif. Nilai signifikansi sebesar $0,00<0,05$ berarti kedua kelompok variabel tersebut memiliki hubungan yang signifikan. Untuk korelasi kanonikal antar variabel terikat terhadap variabel 
bebas, didapatkan angka 0,094 atau 9,4\% yang berarti korelasi yang sangat lemah. Hal ini menunjukkan bahwa hubungan antara variabel bebas dengan variabel terikat merupakan hubungan satu arah.

Tabel 2 Proportion of Variance Explained

\begin{tabular}{|l|r|r|r|r|}
\hline Canonical Variable & Set 1 by Self & Set 1 by Set 2 & Set 2 by Self & Set 2 by Set 1 \\
\hline 1 & .693 & .635 & .313 & .287 \\
2 & .307 & .003 & .266 & .002 \\
\hline
\end{tabular}

Tabel 2 menunjukkan bahwa varian dari variabel terikat yang dapat dijelaskan oleh variabel bebas adalah sebesar 0,635 atau 63,5\% dan varian dari variabel bebas yang dapat dijelaskan oleh variabel terikat adalah sebesar 0,287 atau 28,7\%. Sebaliknya, varian variabel bebas yang dapat dijelaskan oleh varian variabel terikat adalah sebesar 0,002 atau 0,2\%. Hal ini menunjukkan pengaruh satu arah antara variabel bebas dengan variabel terikat, di mana varian dari variabel bebas dapat menjelaskan varian dari variabel terikat, tetapi varian variabel terikat tidak dapat menjelaskan varian dari variabel bebas.

Berdasarkan hasil yang didapat di atas, dapat dilihat bahwa kelompok variabel bebas dan kelompok variabel terikat memiliki korelasi positif yang kuat dan varians dari kelompok variabel bebas dapat menjelaskan varians dari variabel terikat sebesar 63,5\%. Dengan demikian $\mathrm{H}_{1}$ dan $\mathrm{H}_{2}$ diterima, di mana pelatihan berpengaruh positif terhadap kinerja keuangan perusahaan dan modal intelektual perusahaan berpengaruh positif terhadap kinerja keuangan perusahaan.

Pelatihan memiliki pengaruh yang positif terhadap kinerja keuangan perusahaan. Hal ini senada dengan sejumlah penelitian yang terdapat dalam literatur. Dalam penelitian ini, sektor perbankan merupakan industri yang terspesialisai (specialized industries) sehingga pelatihan yang diberikan kepada karyawan perusahaan perbankan pada umumnya digolongkan dalam pelatihan khusus. Pelatihan khusus ini mendukung kinerja perusahaan karena lebih tepat sasaran dan hanya dapat diterapkan dalam perusahaan-perusahaan dalam indsutri yang sejenis. Pelatihan yang dilakukan oleh perusahaan perbankan juga pada umumnya merupakan pelatihan internal yang meningkatkan pembelajaran karyawan karena dilakukan di tempat bekerja dan dapat dengan segera diaplikasikan pada pekerjaan rutinnya. Hal ini mempercepat hasil dari pelatihan sehingga dapat mempengaruhi kinerja keuangan perusahaan secara positif (Becker, 1975; Aragon, Valle dan Sanchez, 2003; Dermol dan Cater, 2013).

Modal intelektual berpengaruh positif terhadap kinerja keuangan perusahaan. Hal ini sesuai dengan beberapa penelitian terdahulu pada perusahaan perbankan dan beberapa perusahaan non perbankan di negara lain. Dalam penelitian ini, pengaruh modal intelektual terhadap kinerja keuangan didukung oleh korelasi dan pengaruh yang kuat dari modal manusia (HCE) dan modal yang digunakan (CEE). Modal structural (SCE) pada penelitian ini menunjukkan korelasi dan pengaruh yang lemah. Berdasarkan hasil tersebut, perusahaan perbankan di Indonesia telah berhasil memanfaatkan kualitas dari sumber daya manusia dan modal yang dimiliki perusahaan untuk menghasilkan kinerja keuangan yang baik, tetapi perusahaan perbankan di Indonesia belum bisa memaksimalkan modal struktural yang dimiliki perusahaan. Keadaan ini serupa dengan keadaan perusahaan perbankan di Turki, Luksemburg, Tanzania dan Belgia pada beberapa penelitian terdahulu. (Mention dan Boris, 2013; Yildiz, Meydan dan Guner, 2014; Ozkan, Cakan dan Kayakan, 2016).

Pengaruh yang signifikan dan positif dari modal manusia mendukung beberapa penelitian terdahulu. Hal ini menunjukkan bahwa perusahaan perbankan di Indonesia telah berhasil memanfaatkan kemampuan intelektual karyawannya secara maksimal untuk menghasilkan nilai bagi perusahaan. Keberhasilan perusahaan 
perbankan di Indonesia untuk mengeluarkan potensi dari karyawan secara maksimal tidak luput dari kesadaran para karyawannya untuk menempatkan diri sebagai pemegang kepentingan perusahaan. Dengan demikian, setiap karyawan akan berusaha sebaik-baiknya agar dapat menghasilkan nilai bagi perusahaan (Ulum, Chariri dan Ghozali, 2008; Sidharta dan Affandi, 2016)

Kondisi di mana modal struktural memiliki pengaruh yang lemah terhadap kinerja keuangan perusahaan di Indonesia tidak menguntungkan perusahaan karena perusahaan belum dapat mengintegrasikan kemampuan sumber daya manusia ke dalam struktur perusahaan, sehingga apabila karyawan yang kompeten keluar dari perusahaan, hal ini akan mempengaruhi kompetensi yang dimiliki perusahaan. Hal ini juga dapat berarti bahwa sumber daya manusia yang dimiliki perusahaan belum dapat dimanfaatkan secara maksimal karena menurut literature yang ada, modal struktural yang baik hendaknya dapat mengoptimalkan kinerja intelektual yang dimiliki karyawan sehingga karyawan tersebut dapat mengeluarkan potensi yang dimilikinya secara penuh. Kurang berpengaruhnya modal struktural bagi perusahaan perbankan di Indonesia diduga karena masih banyaknya campur tangan pemerintah dalam kebijakan perbankan, yang pada umumnya dilakukan melalui Bank Indonesia. (Becker, 1975; Ulum, Chariri dan Ghozali, 2008; Gruian, 2011).

Modal yang digunakan (CEE) berpengaruh cukup kuat dan positif terhadap kinerja keuangan perusahaan. Hal ini menunjukkan bahwa kinerja keuangan perusahaan dipengaruhi oleh modal fisik yang dimiliki perusahaan. Hasil tersebut sesuai dengan hasil penelitian-penelitian terdahulu yang menyatakan bahwa CEE berpengaruh positif terhadap kinerja keuangan perusahaan sehingga hasil penelitian ini telah sesuai dengan teori yang ada (Ulum, Chariri dan Ghozali, 2008; Gruian, 2011; Mention dan Boris, 2013; Yildiz, Meydan dan Guner, 2014; Ozkan, Cakan dan Kayakan, 2016; Sidharta dan Affandi, 2016; Pratama, 2016).

Hasil penelitian ini berbeda dengan hasil yang didapat oleh penelitian serupa terhadap perusahaan eksportir di Serbia. Perbedaan ini terjadi karena perusahaan-perusahaan eksportir di Serbia tersebut terkena dampak dari resesi global tahun 2008, sementara perusahaan perbankan di Indonesia pada periode penelitian berhasil selamat dari dampak keadaan serupa yang terjadi pada tahun 2012. Selamatnya perusahaan perbankan di Indonesia merupakan salah satu dari hasil kebijakan yang dikeluarkan Bank Indonesia sehubungan dengan menyikapi resesi tahun 2012 tersebut. Kebijakan tersebut terbukti efektif menyelamatkan perekonomian Indonesia dari resesi tersebut (Janosevic dan Dzenopoljac, 2012).

\section{KESIMPULAN DAN SARAN}

Berdasarkan uraian dari pembahasan dan hasil analisis data pada bab sebelumnya, kesimpulan yang dapat diambil adalah sebagai berikut:

1. Diterimanya hipotesis pertama menjawab pertanyaan mengenai pengaruh pelatihan terhadap kinerja keuangan perusahaan. Pelatihan yang diasumsikan diberikan pada awal periode berpengaruh positif terhadap kinerja keuangan yang dinilai pada akhir periode yang bersangkutan. Maka, perusahaanperusahaan tidak perlu ragu untuk memberikan pelatihan, baik pelatihan umum maupun khusus kepada karyawannya karena pelatihan ini akan meningkatkan kinerja karyawan yang berujung pada meningkatnya kinerja keuangan perusahaan.

2. Diterimanya hipotesis kedua menjawab pertanyaan mengenai pengaruh modal intelektual perusahaan terhadap kinerja keuangan perusahaan. Modal intelektual perusahaan berpengaruh positif terhadap kinerja keuangan perusahaan. Hal ini menunjukkan bahwa modal intelektual yang dimiliki perusahaan merupakan elemen yang penting bagi perusahaan untuk memperoleh keunggulan 
kompetitif dalam bersaing di pasar, menciptakan nilai bagi perusahaan dan meningkatkan kinerja keuangan perusahaan.

Penelitian ini memiliki keterbatasan, yaitu hanya menguji perusahaan dari industri perbankan dan penelitiannya dilakukan pada periode-periode pasca krisis ekonomi global sehingga hasilnya dapat dipengaruhi oleh kondisi eksternal. Untuk penelitian selanjutnya, disarankan untuk menggunakan periode yang normal, sehingga hasilnya dapat lebih menggambarkan pengaruh pelatihan dan kinerja keuangan perusahaan pada kondisi ekonomi yang normal.

Penelitian ini juga memiliki keterbatasan dalam hal periode dilakukannya pelatihan. Dalam penelitian ini, pelatihan diasumsikan dilakukan di awal periode tetapi pada kenyataannya belum tentu semua pelatihan dilakukan pada awal periode. Berdasarkan hal tersebut, maka akan lebih baik jika penelitian selanjutnya mempertimbangkan waktu dilaksanakannya pelatihan secara lebih akurat agar mendapatkan hasil yang lebih baik.

\section{DAFTAR PUSTAKA}

Aguinis, H. \& Kraiger, K. (2009). Benefits of Training and Development for Individuals and Teams, Organizations, and Society. The Annual Review of Psychology 2009 (60). 451 - 474.

Anonim (2016, June 21). Riset Temukan Kualitas CSR Perusahaan Indonesia Rendah. CNN Indonesia. Retrieved from http:/www.cnnindonesia.com/nasional/20160721074144-20-146030/riset-temukankualitas-csr-perusahaan-indonesia-rendah/

Aragon, M. I. B., Jimenez, D.J., Valle, R. S. (2012). Training and performance: The mediating role of organizational learning. BRQ Business Research Quarterly 17. $161-173$.

Aragon, M. I. B., Sanchez, A.A., Valle, R. S. (2003). Effect of Training on Business Results. The International Journal of Human Resource Management 14 (6). 956 - 980.

Becker, G. S. (1962). Investment in Human Capital: A theoretical analysis, Journal of Political Economy 70 (5, No.2): 9-49.

Becker, G. S. (1975). Human Capital: A Theoretical and Empirical Analysis, with Special Reference to Education, Second Edition. Retrieved from http://www.nber.org/books/beck75-1

Bishop, J. (1994). The Impact of Previous Training in Schools and on Jobs on Productivity, Required OJT, and Turnover of New Hires, Private Sector and Skill Formation: International Comparisons, edited by Lisa Lynch, National Bureau of Economic Research. Chicago: Univ. of Chicago Press, 161-200.

Chen-Huan, T., Jer, S., Shih-Chien, C.F., (2009). Employment modes, high-performance work practices, and organizational performance in the hospitality industry. Cornell Hospitality Quarterly 50 (4), 413-431.

Ciger, A. \& Topsakal, Y (2016). Intellectual Capital and Financial Performance: Case of Travel Agents. Asian Journal of Social Sciences and Management Studies 3(3): 182 - 190.

Daniel, W. (2016, April 18). Kondisi Bank RI: Kredit Bermasalah Naik, Margin Bunga Tertinggi di ASEAN. Retrieved from https://finance.detik.com/moneter/3190069/kondisi-bank-ri-kredit-bermasalah-naikmargin-bunga-tertinggi-di-asean

Dessler, Garry (2009). Manajemen Sumber Daya Manusia (Jilid 2 Edisi Kesepuluh), Jakarta: Indeks.

Efryns \& Zefanya, K. (2009). Analisis Pengaruh Beban Promosi Serta Beban Pelatihan dan Pengembangan Karyawan Terhadap Kinerja Keuangan Perusahaan (Studi Empiris Pada Perusahaan-perusahaan yang 
Terdaftar di Bursa Efek Indonesia Tahun 2006 dan 2007). Skripsi tidak diterbitkan. Universitas Katolik Indonesia Atma Jaya, Jakarta.

Ghozali, I. (2005). Aplikasi analisis multivariate dengan program SPSS. BP-Universitas Diponegoro, Semarang.

Gruian, Claudiu-Marian (2011). The Influence of Intellectual Capital on Romanian Companies' Financial Performance. Annales Universitatis Apulensis Series Oeconomica, 13 (2): 260 - 272.

Hair, J.F.; Black, W. C.; Babin, B. J.; Anderson; R.E. (2010). Multivariate Data Analysis, A Global Perspective, $7^{\text {th }}$ Edition. Pearson.

Isanzu, J.N. (2015). Impact of Intellectual Capital on Financial Performance of Banks in Tanzania. Journal of International Business Research and Marketing Volume 1 (1): 16 - 23.

Jalilian, O., Hassani, S. R., Ghanbari, M., Jalilian,H.R. \&Moradi, M. (2013). The Relationship between Intellectual Capital and Financial and Non-Financial Performance in West Cement Company in Kermanshah, Journal of Basic and Applied Scientific Research 3(6) 427 - 432.

Lubis, K. A. (2008). Pengaruh Pelatihan dan Motivasi Kerja Terhadap Kinerja Karyawan PT Perkebunan Nusantara IV (Persero) Medan. Tesis tidak diterbitkan. Universitas Sumatera Utara, Medan.

Liputan6.com (2017, Jan 3). Opini: Prospek Ekonomi dan Perbankan Indonesia 2017. Retrieved from http://bisnis.liputan6.com/read/2694027/opini-prospek-ekonomi-dan-perbankan-indonesia-2017

Lutfi, M. (2016, June 16). Sebagian Besar Perusahaan di Indonesia tidak Memiliki Program CSR. Message posted to http://forumcsrkessos.or.id/2016/06/sebagian-besar-perusahaan-di-indonesia-tidak-memilikiprogram-csr/

Sarwono, Jonathan (2017). Mengenal Prosedur-Prosedur Populer dalam SPSS 23. Jakarta: Kompas Gramedia. Sastradipoera, Komarudin (2004). Strategi Manajemen Bisnis Perbankan. Bandung: Kappa-Sigma.

Sidharta, I. \& Affandi, A. (2016). The Empirical Study on Intellectual Capital Approach toward Financial Performance on Rural Banking Sectors in Indonesia. International Journal of Economics and Financial Issues 6(3): 1247-1253.

Supangkat, Harry (2003). Buku Panduan Direktur Keuangan, Edisi 1. Salemba Empat. Jakarta.

Ozkan, N.; Cakan, S.; Kayacan, M. (2016). Intellectual capital and financial performance: A study of the Turkish Banking Sector. Borsa Istanbul Review xx (2016). 1 - 9.

Pratama, Bima C. (2016). The Impact of Intellectual Capital of Indonesian's High-Tech Company on Firm's Financial and Market Performance. International Journal of Academic Research in Accounting, Finance and Management Sciences 6(4): $73-81$.

Ranani, H. S. \& Bijani, Z. (2014). The Impact of Intellectual Capital on the Financial Performance of Listed Companies in Tehran Stock Exchange. International Journal of Academic Research in Accounting, Finance and Management Sciences, 4(1): 119 - 127.

Rayanti, D. (2016, May 19). Ekonomi RI Melambat, Kredit Bermasalah Bank Naik. Retrieved from https://finance.detik.com/moneter/3214116/ekonomi-ri-melambat-kredit-bermasalah-bank-naik

Reeve, J. M., Warren, C. S., \& Duchac, J. (2012). Principles of Financial Accounting 12th Edition International. Cengage Learning.

Thang, N. N., \& Buyens, D. (2008). What We Know About Relationship Between Training and Firm Performance: A Review of Literature. Vlerick Leuven Gent Working Paper Series 2009/01: 1 - 34.

Triyono, A. (2016, May 25). CSR akan diwajibkan ke semua perusahaan. Kontan. Retrieved from http://nasional.kontan.co.id/news/csr-akan-diwajibkan-ke-semua-perusahaan

Ubeda-Garcia, M., Cortes, E. C., Marco-Lajara, B., \& Zaragoza-Saez, P. (2014). Strategy, Training and Performance Fit. International Journal of Hospitality Management 42 (2014). 100-116. 
Ulum, I., Chariri, A., \& Ghozali, I. (2008). Intellectual Capital dan Kinerja Keuangan Perusahaan: Suatu Analisis Pendekatan Partial Least Square. Universitas Tanjung Pura Pontianak.

Yildiz, S., Meydan, C., \& Gunner, M. (2014). Measurement of Intellectual Capital Components Through Activity Reports of Companies. Procedia - Social and Behavioral Sciences 109 (2014). 614 - 621.

Augurzky, B. \& Schmitz, H. (2010). Is there a Future for Small Hospitals in Germany?. LeibnizInformationszentrum Wirtschaft Leibniz Information Centre for Economics 198 (2010). 1 - 17.

Hall, R. E. (2002). Dynamics of Corporate Earnings. Hoover Institution and Department of Economics, Stanford University. 